\title{
El impacto de la crisis económica en nuestras dos constituciones ${ }^{1}$
}

\author{
Javier García Roca \\ Catedrático de Derecho Constitucional, UCM \\ groca@der.ucm.es \\ Miguel Ángel Martínez Lago \\ Catedrático de Derecho Financiero y Tributario, UCM \\ mamlago@ucm.es
}

\begin{abstract}
Resumen
Este trabajo recoge el texto de la conferencia pronunciada por Javier GARCÍA ROCA en el Centro de Estudios Políticos y Constitucionales el 30 de enero de 2014. Aquel compromiso sirvió para exponer las principales tesis de nuestra monografía: Estabilidad presupuestaria y consagración del freno constitucional al endeudamiento (Civitas- Thomson Reuters, 2013). Por eso decidimos que este artículo viniera firmado por ambos autores. Ahora tratamos de propiciar la discusión sobre la transformación que la crisis económica está dejando en problemas que ya teníamos desde hace tiempo y que han empeorado y aflorado prácticamente a la vez, después de treinta y cinco años de desarrollo constitucional. La crisis ha introducido en el Derecho de la Unión Europea y en nuestro ordenamiento interno —con la reforma del artículo 135 de la Constitución- un reforzado principio de estabilidad presupuestaria, una verdadera prohibición de rango constitucional. A nivel europeo asistimos a un lugar constitucional material, que es donde se encuentran las decisiones políticas básicas y supremas respecto de la economía. $Y$ a nivel interno se hace urgente emprender una reforma constitucional como mecanismo de defensa de la Constitución, con el fin de evitar el apagón del circuito democrático representativo.
\end{abstract}

\section{The impact of the economic crisis in our two constitutions}

\section{Abstract}

This paper presents the text of the conference pronounced by Javier García Roca at the Center of Political and Constitutional Studies, on January 30, 2014. That commitment served to expose the main thesis of our essay: Budgetary stability and constitutional consecration of debt brake (Civitas-Thomson Reuters, 2013). So we decided we both would sign this article. Now we try to stimulate discussion about the transformation of the economic crisis is leaving problems that we had long and have gotten worse and emerged practically at once, after thirty-five years of constitutional development. The crisis has introduced in the law of the European Union and in our domestic legislation -with the reform of Article 135 of the Constitution - a stronger principle of budget stability, a true constitutional prohibition. At European level, we are witnessing a material constitutional place, that is where there are the basic and supreme political decisions about the economy. And at the domestic level it is urgent to undertake a constitutional reform, as a defense of the Constitution, in order to avoid the blackout of the representative democratic system.

Palabras clave

Constitución, Crisis económica y financiera, Estabilidad presupuestaria, Reforma constitucional, Unión Europea.

Keywords

Constitution, Economic and Financial Crisis, Budgetary Stability, Constitutional Reform, European Union.

Sumario: 1. INTRODUCCIÓN.2. LA REFORMA CONSTITUCIONAL DEL ART. 135 CE: EL PRINCIPIO DE ESTABILIDAD PRESUPUESTARIA O SOSTENIBILIDAD FINANCIERA.3. LA CONSTITUCIÓN EUROPEA: UN DERECHO CONSTITUCIONAL ECONÓMICO SIN CONSTITUCIÓN.4. EL DESARROLLO EN UNA ESPECÍFICA LEY ORGÁNICA DEL ARTíCULO 135 CE.5. LA CONSTITUCIÓN DOMÉSTICA: UNA CONSTITUCIÓN SIN APENAS DERECHO CONSTITUCIONAL.6. CONCLUSIÓN.

$1 \quad$ El presente trabajo recoge el texto de la conferencia pronunciada por Javier GARcía RocA en el Centro de Estudios Políticos y Constitucionales el 30 de enero de 2014. En buena medida, aquel compromiso sirvió para exponer las principales tesis de nuestra monografía: Estabilidad presupuestaria y consagración del freno constitucional al endeudamiento (Civitas-Thomson Reuters, 2013) y por eso decidimos que este artículo viniera firmado por ambos. No obstante, hemos preferido mantener la forma — provocadora y sintética- de una intervención oral, tal y como el trabajo fue diseñado, si bien lo redactamos ahora en primera persona del plural. Por la misma razón creemos estar dispensados de la necesidad de reflejar ahora el amplio aparato bibliográfico que puede consultarse en nuestro libro. 


\section{INTRODUCCIÓN}

La encomienda que nos formula amablemente Santiago MUÑOz MACHADO es inabordable en unos pocos minutos: tratar el impacto de la crisis económica —no sólo española, sino europea y global— en la Constitución. Nos limitaremos a dar unas pinceladas impresionistas que permitan propiciar la discusión. No hay tiempo de describir de forma objetiva la realidad de esa transformación, sino únicamente de explicar la sensación que la crisis ha dejado en nuestra retina de iuspublicistas y a la luz de los treinta y cinco años de desarrollo constitucional. Esta crisis no ha sido - no está siendo - un episodio nacional más, sino un salto cualitativo o de grado en los problemas que ya teníamos desde hace tiempo y que ahora han empeorado y aflorado prácticamente a la vez.

Es de suponer que los organizadores querían que explicáramos nuestra monografía sobre la Estabilidad presupuestaria y consagración del freno constitucional al endeudamiento. Un estudio al que reenviamos y que se ocupa de la reforma constitucional del artículo $135 \mathrm{CE}$, de su desarrollo legal y del nuevo Derecho europeo en la materia.

Pero al hilo de esa síntesis, formularemos algunas reflexiones nuevas, que dejaremos simplemente apuntadas para alcanzar un diagnóstico de la situación. El impacto constitucional de la crisis ha sido transversal y en múltiples campos y nos ha hecho ver, como en la vieja fábula del traje nuevo del emperador, que el Rey está realmente desnudo, que el Estado y muchas de sus instituciones están seriamente dañadas en su legitimidad democrática, o desprovistos de eficiencia, o de ambas cosas a la vez, y no vestidas con lujosas ropas ${ }^{2}$. Al modo de una lupa que incrementa el tamaño de los defectos, la crisis ha descosido las costuras del traje constitucional, ya muy deteriorado por el transcurso del tiempo y la ausencia de un mantenimiento constante mediante paulatinas reformas como algunos hemos venido denunciando desde hace tiempo. Tememos hacernos ahora preguntas que no podemos contestar y probablemente tampoco muchos de ustedes.

\section{LA REFORMA CONSTITUCIONAL DEL ART. 135 CE: EL PRINCIPIO DE ESTABILIDAD PRESUPUESTARIA O SOSTENIBILIDAD FINANCIERA}

La consecuencia más evidente de la crisis financiera ha sido la introducción en el Derecho de la Unión y en la Reforma constitucional del artículo 135 CE de un reforzado principio de estabilidad presupuestaria. Una prohibición de rango constitucional. Veamos varios problemas.

La justificación cultural de la sostenibilidad financiera. Son varios los interrogantes que surgen: ¿La prohibición o freno al endeudamiento es una regla jurídica neutra o hemos consagrado en la Constitución una ideología liberal en la dirección política de la economía? ¿Se impide una alternativa entre políticas más liberales o socialdemócratas? ¿Hemos enterrado a KEYNES en provecho de HAYEK Y BUCHANAN? Existe un cierto consenso europeo en la necesidad de frenar la proclividad de los gobiernos a gastar e incrementar constantemente los servicios públicos sin atreverse a subir los impuestos por razones electorales. También lo hay en censurar que no se aprovechen los momentos altos del ciclo económico para pagar la deuda. La desfiscalización de los ingresos públicos es racionalmente imposible. Los orígenes liberales de esta nueva estabilidad presupuestaria son evidentes; es claro en el llamado "ordoliberalismo" de la Escuela de Friburgo y sobre todo en el pensamiento del Premio Nobel James BUCHANAN y su "constitutional choice" que hemos revisado. Pero su introducción en Suecia, un Estado de bienestar de referencia, es un ejemplo de que la regla se está haciendo transversal por encima de las ideologías. Ningún Estado puede endeudarse de forma permanente ni se puede deber más del 60\% de lo que uno tiene. Y España está ya por encima del 90\% y llegará en 2014 a casi el 100\%. ¿Quién va a pagar todos esos préstamos de los mercados y en cuánto tiempo?

Las finanzas públicas deben inevitablemente ser sostenibles, como ya hemos acabado por admitir con el medio ambiente, de donde procede la idea de "sostenibilidad" que nos ocupa en su construcción en Alemania. No cabe una demanda constante al alza de los servicios públicos y de las prestaciones del Estado de bienestar, porque sencillamente no puede pagarse. Pero tampoco deberíamos desembocar los europeos en lo que STIGLITZ ha reprochado y llamado "fetichismo del déficit": un culto o veneración excesiva.

¿Una regla jurídica o una obligación política? Un segundo problema consiste en resolver si el freno al endeudamiento debería ser una regla jurídica, una prohibición constitucional que refuerce las anteriores prohibiciones legales, o habría bastado con una obligación política. La experiencia alemana antes de su última reforma constitucional parece haber demostrado que, sin una estricta vinculación a una prohibición con escaso margen de maniobra, los políticos — que viven de los votos - tienden a saltarse estos límites presupuestarios. También en Italia se ha dicho que hemos construido una fuerte regla jurídica ante la realidad de que los acuerdos o convenciones políticas se incumplen con frecuencia.

2 Vid. Javier GARcía RocA y José ESTEVE PARDo: “Algo estamos haciendo mal” en El País, la cuarta página, jueves 20 de febrero de 2014, p. 29, que recoge las conclusiones de este seminario en el CEPC. 
El tiempo de los ajustes. Pero estas dos afirmaciones no contestan a la pregunta del lapso de tiempo necesario para hacer los ajustes que Ileven al equilibrio presupuestario. Cuesta creer que debiera hacerse a la carrera, como hemos hecho, y no mediante una planificación ordenada y con un ritmo sostenido y constante de transición. Sorprende que los españoles no empezáramos a hacer recortes presupuestarios en 2007, cuando el trazado de la senda del equilibrio en las normas de la Unión Europea era ya clara. Quizás somos un país bárbaro, incapaz de hacer ajustes financieros de manera racional, o de reformar lenta y constantemente nuestra Constitución y nuestras demás normas - las presupuestarias entre ellas_, y hemos empezado a hacerlos con la amenaza de una soga al cuello tendida desde Europa y antes de ahorcarnos y declararnos rescatados por la Unión, el famoso "bail out".

¿Topes cuantitativos de déficit y endeudamiento? Los umbrales de déficit y deuda pública fijados en el Derecho de la Unión y a los que la Constitución remite - y asimismo regula la Ley Orgánica de Estabilidad Presupuestaria y Sostenibilidad Financiera - pueden verse como algo aleatorios y su cuantificación podría no considerarse indiscutible. Pero su progresiva reducción en las normas - porque, en la realidad, la deuda pública se ha disparadomuestra que la tendencia es clara: alcanzar el equilibrio o incluso el superávit. Una disciplina presupuestaria en el futuro como indicio de una buena administración.

¿Es la estabilidad presupuestaria compatible con el Estado social y el Estado autonómico? Una Reforma constitucional parcial o inacabada. Ésta es la gran pregunta. Una vez admitida la validez de la regla del freno al endeudamiento, habrá que hacer un esfuerzo por hacer compatibles tres principios igualmente constitucionales y no menos importantes: Estado social, fuerte descentralización política y suficiencia financiera.

Pero mucho nos tememos que esta compatibilidad sea imposible sin efectuar serios ajustes en el confuso e impreciso sistema de competencias territoriales en que se funda el Estado autonómico y que alberga unas reglas manifiestamente mejorables. También en las normas de financiación autonómica que deben ser pactadas de nuevo y ajustadas, en particular los mecanismos de compensación y solidaridad interterritorial, y verdaderamente ligadas a unas competencias previamente clarificadas. Así como en la regulación y ordenación de las prestaciones y servicios públicos que dispensan las Comunidades Autónomas, que, por definición, son Administraciones de gasto, al estar en sus manos muchas prestaciones sociales esenciales como son la sanidad, la educación o la asistencia social. Nos sorprende por eso la frivolidad con la que algunas personas públicas afirman tranquilamente que no merece la pena reformar la Constitución para ordenar las competencias de una Comunidad Autónoma... Sólo que no se trata de las competencias de cualquier nacionalidad o región, por sí mismas muy respetables, sino las de toda España. Y esta labor de poner orden en la casa común y en las potestades de actuación de cada ente resulta imprescindible desde hace mucho tiempo para alcanzar una racionalidad en el gasto. Las competencias territoriales no funcionan suficientemente bien y no pueden seguir siendo un laberinto que impida actuar racional y eficazmente al Estado en su conjunto en infinidad de concretas materias, generando constantemente más conflictos competenciales que en cualquier país de nuestro entorno. Perdemos un tiempo preciado en resolver qué ente tiene la competencia y que deberíamos destinar a saber cómo conviene actuar.

Tampoco debería bastar con realizar a la carrera ajustes presupuestarios en todos los terrenos, con una tijera de podar y para todos, de manera niveladora o excavadora, en vez de aprovechar la oportunidad que concede la crisis para acometer una verdadera racionalización del Estado y de sus gastos, sin improvisaciones, y tras serios estudios e informes sobre los fallos. La eficiencia en el gasto debe ser la primera causa del equilibrio. Tomemos como ejemplo las titulaciones universitarias: ¿Es mejor tener media docena de empobrecidas Facultades de Derecho en la Comunidad de Madrid o albergar un par de ellas que se hallen entre las mejores del mundo mediante su fusión? ¿Podemos tener una Universidad pública en cada provincia y centenares de titulaciones sin apenas alumnos? ¿Tenemos valor para pactar y hacer a medio plazo estas reformas estructurales necesarias? Otro tanto podría decirse de ocho millares de municipios, de una cincuentena de provincias sin competencias precisas y de una multiplicidad de entes locales intermedios, o de aeropuertos sin viajeros, de autopistas privadas de pago, con concesionarios pero sin coches, y cuyas pérdidas acaba pagando el Estado, de Cajas de Ahorro mal gestionadas al venir tuteladas con criterios políticos y no bancarios, y de tantas cosas cuyo desorbitado gasto ha ido creciendo mediante improvisaciones coyunturales como una fronda, sin que nadie asuma su responsabilidad política por la mala gestión. Esta transparencia y rendición de cuentas ("accountability") es la cultura política y jurídica que nos falta. Tomemos en serio el dinero público porque no es inagotable.

El Estado social probablemente pueda preservarse acometiendo modificaciones. Una mayor austeridad donde sea menester, pues los derechos sociales no tienen por qué ser baratos — tampoco lo es la defensa nacional, o la representación exterior, o la administración de justicia- pero deben ser austeros y es preciso impedir los abusos y los lujos si los hubiere. Con una mejor gestión, una revisión de los beneficios concedidos, optando por los básicos, una mayor inspección en el uso de las prestaciones, una mejor coordinación y colaboración de las Administraciones implicadas, y algunas leyes razonables debería poder salvarse, aunque se está transformando a 
pasos agigantados.

En cambio, el Estado autonómico necesita algunos arreglos que no pueden hacerse sin una reforma de la Constitución como cualquier experto sabe. No para cambiar bruscamente el sentido de la marcha y volver al viejo centralismo — un camino que desapareció hace tiempo_-, sino para subir a la Constitución más de tres décadas de experiencias en defectos y conflictos constitucionales. Es menester solventar problemas muy graves de concurrencia de competencias en un mismo espacio, o de déficit en los títulos competenciales, así como alcanzar una mínima estabilidad de un sistema de financiación debidamente pactado. En efecto, la financiación autonómica debería llevarse en parte a la Constitución, que apenas dice nada sobre este tema, por razones de estabilidad y pacificación del conflicto, como se hace en Alemania donde se reforma constantemente. No olvidemos que la reforma de la estabilidad presupuestaria estuvo ligada en Alemania a la reforma del federalismo y del Estado social. Nosotros nos hemos traído sólo una pata del trípode, y ni nos planteamos la necesidad de acuerdos parlamentarios y/o de grandes coaliciones de gobierno para poder hacer ciertas reformas graves. Precisamente por eso no las hacemos.

La dolorosa situación de la integración nacional en Cataluña no ha sido generada, claro está, por la crisis económica, sino por varias razones inherentes a nuestra historia y compleja configuración estatal. No lo podemos afrontar ahora, pero qué duda cabe de que el montante de la fuerte deuda pública catalana (nada menos que 45.149 millones de euros en 2012, un 22,81\% de la deuda regional) parece haber acrecentado las hostilidades y los reproches. Alguien debería preguntarse en Cataluña, de un lado, si esta desproporcionada deuda deriva realmente de la solidaridad financiera interterritorial —el llamado "expolio fiscal" — o de una inapropiada gestión del autogobierno y de las propias culpas. Pero, de otro, no es menos necesario recordar que si la Constitución española se hubiera reformado en su momento, acaso el Estatuto de Cataluña de 2006 no hubiera intentado una —imposible- reforma constitucional mediante su mutación en el Estatuto de una sola Comunidad; generando las frustraciones que su declaración parcial de inconstitucionalidad en la STC 31/2010 produjo en Cataluña. Cerrar la puerta a la reforma constitucional como fuente del Derecho produce constantes problemas.

No se defiende la Constitución, en ningún otro lugar, parapetándose detrás de ella, sino alcanzando acuerdos y modificándola constantemente. Es precisa una voluntad de diálogo que permita transacciones y compromisos y que lleve a un nuevo pacto constitucional con eficacia integradora. No reformar la Constitución es un lento suicidio por todas estas razones... No puede bastar con incorporar la sostenibilidad financiera sin reformar la Constitución territorial y sin adecuar a la necesaria austeridad las dimensiones de nuestro Estado social que son los otros dos ingredientes del modelo. La reforma constitucional comenzada en 2011 ha sido sólo parcial o incompleta y está inacabada. Pero cuesta mucho advertirlo.

Una Reforma constitucional derivada. Casi todo lo que dice el artículo 135 CE en 2011 estaba ya en el Derecho Europeo desde 2007 y poco después se recogería en el Tratado de Estabilidad Coordinación y Gobernanza de 2012. Un compromiso europeo de frenar el endeudamiento. Una vez adoptada la decisión política en la Unión, la Reforma era correcta y casi inevitable, puesto que la mutación constitucional ya se había producido cuatro años antes.

Compromiso con Europa y con los mercados. No obstante, el artículo 135 CE fortalece la vinculación de todas las Administraciones públicas con ese compromiso europeo. El rango constitucional de la prohibición establece una obligación con la más alta vinculación normativa posible, si bien habría bastado con que se produjera en la ley según el Derecho de la Unión. Todo ello tiene también una eficacia simbólica y política para los mercados, los acreedores privados. Tras la unión monetaria y la creación del sistema europeo de bancos centrales, los Estados miembros no pueden asegurar la financiación de sus déficits emitiendo moneda, o devaluándola, y dependen de la confianza de los acreedores privados, la temida prima de riesgo.

Imprevisión de controles. Pero la indeterminación de la Reforma sobre los controles en caso de incumplimiento de los límites es un claro defecto. Sentamos un compromiso constitucional que no introduce sanciones al incumplimiento por las Comunidades Autónomas y los Entes Locales. Hemos llamado a esta omisión la paradoja de haber olvidado lo más importante. ¿Fue una sabia prudencia de la Reforma o, por el contrario, revela una injustificable precipitación? Mucho nos tememos que sea lo segundo. La Ley Orgánica rellenó esta laguna pero, como veremos, no lo hizo en el mejor sentido de los posibles.

Regla de oro: una prohibición constitucional y una norma de principios. El artículo 135 CE no es un precepto constitucional más. No cabe seguir una interpretación sistemática como criterio de la interpretación constitucional cuando esté en juego esta regla. La prohibición se aplica con preferencia y desplaza a las demás normas constitucionales. Esto es muy nuevo. Por otro lado, la regla de freno al endeudamiento no sólo tiene una finalidad impeditiva, como toda prohibición, sino asimismo impositiva. Es asimismo una norma de principios que orienta el funcionamiento de todas las Administraciones públicas. De aquí deben extraerse consecuencias ulteriores e 
impulsar algunas reformas organizativas y estructurales. Valga una muestra: deberíamos tomarnos en serio la confección de la memoria económica que debe acompañar a cualquier proyecto de ley, calculando su impacto financiero - una exigencia que a menudo no se cumple bien-y permitir que la Comisión de Presupuestos del Congreso pudiera informar a las otras comisiones parlamentarias legislativas sobre ese impacto como ocurre en Italia; o simplemente poner en marcha de verdad la Oficina Presupuestaria de las Cortes Generales que languidece no se sabe por qué razones.

Ventajas e inconvenientes de la Reforma. El inconveniente principal ha sido la acusada precipitación. No hubo siquiera un debate sobre si era una materia constitucional o legal como ocurrió en Polonia. Un impulso del Presidente ZAPATERO, presionado por la intranquilidad de la Unión, pero sorprendente en los tiempos incluso para los propios miembros de su gobierno. Hemos aprobado la reforma constitucional más importante sin debatirla y a la carrera. Es esta una mala práctica que no debiera tomarse en el futuro como precedente, pues supone una peligrosa desvalorización del procedimiento constitucional de reforma. Sin embargo, esos sabios trámites de procedimiento no son formalidades engorrosas sino que otorgan legitimidad democrática a las decisiones mediante discusión y publicidad y permiten asegurarse de la corrección técnica de las mismas, evitando defectos que ciertamente albergan la Reforma y la ley que la desarrolla. Un error de neófitos en democracia. No existió un informe previo del Consejo de Estado, ni una verdadera comisión parlamentaria de estudio e informe. Se aprobó en apenas dos horas y cuarenta minutos, a caballo de dos procedimientos especiales: lectura única y procedimiento de urgencia. No extraña pues que a la Reforma se le olvidara prever controles y sanciones en caso de incumplimiento de los topes de déficit y deuda por parte de las Comunidades Autónomas o de los Entes Locales. En efecto, la Reforma del artículo 135 CE no atina a ubicar el supuesto entre los artículos 153 y 155 CE —respectivamente, los controles sobre los actos o sobre los órganos-y, sin embargo, debió hacerlo en un lógico paralelismo al introducir un mecanismo nuevo o una variante muy relevante de uno viejo.

No obstante, las ventajas de la Reforma son ciertas. Se ha calmado la prima de riesgo y a los acreedores, mejorando las condiciones de la financiación privada del Estado. Y la economía y el sistema bancario han salido del colapso. Si bien, en ambas cosas, mucho ha tenido que ver la actitud del Banco Central Europeo. Además, se ha invertido la tendencia -irresponsable - a creer que el gasto estatal no posee límites y puede ocuparse de todo. Por ende, algunos especialistas extranjeros, con el distanciamiento que puede presumirse en ellos, consideran que la Reforma muestra un buen equilibrio técnico entre certeza y disciplina presupuestaria.

Una decena de reglas. La constitucionalización del principio de estabilidad presupuestaria en el artículo 135 se ha realizado incorporando una decena de variadas normas:

- La consagración del principio.

- Las dos prohibiciones de déficit y deuda.

- El reenvío a la Unión y a la Ley Orgánica para fijar esos topes o valores de referencia.

- La necesidad de una autorización por ley para emitir deuda pública.

- La preferencia del pago de la deuda. La prohibición de enmienda de esos créditos.

- Ciertas excepciones: catástrofes, recesión, emergencia.

- Una reserva constitucional de algunas materias y una habilitación expresa a una Ley Orgánica.

- Un mandato a las Comunidades Autónomas de adaptar sus disposiciones para hacer efectivo el principio.

Es, sobre todo, bueno que no se fijaran porcentajes o umbrales expresos en la Constitución y que se reenviara a los márgenes establecidos por la Unión para los Estados miembros. Si bien, las excepciones constitucionalmente previstas no se están aplicando en la actual situación de recesión económica, por la rigidez de los objetivos de la política europea.

La función constitucional de la Ley Orgánica. A nuestro juicio, una de las consecuencias principales de la Reforma es que, en virtud de la reserva constitucional de ciertas materias —entre otras cosas, la responsabilidad por incumplimiento y la metodología del cálculo del déficit estructural—y de la elección de una habilitación expresa, esta específica Ley Orgánica pasa a formar parte del bloque de la constitucionalidad. Puede por ello pensarse que cumple una función constitucional, al igual que ocurre con la LOFCA o con la Ley de Presupuestos. En virtud de dicho criterio, debería poder desplazar los mandatos de otras leyes e incluso de los Estatutos de Autonomía en casos de conflictos normativos, con la finalidad de hacer efectivos los mandatos constitucionales. La Ley Orgánica de Estabilidad Presupuestaria y Sostenibilidad Financiera concreta la Constitución, mediante un desarrollo legal indefectible que es una prolongación de las funciones constitucionales. El Tribunal Constitucional debería aclarar 
este decisivo extremo, su lugar y naturaleza jurídica entre las fuentes del Derecho, lo antes posible.

\section{LA CONSTITUCIÓN EUROPEA: UN DERECHO CONSTITUCIONAL ECONÓMICO SIN CONSTITUCIÓN}

La estabilidad presupuestaria es una decisión política "constitucionalizada" en la Unión. Pero la revisión de las normas constitucionales españolas fue claramente anterior a la Reforma constitucional de 2011 y se ha venido haciendo en sede europea desde 2007. Es pues la nuestra una Reforma "derivada", ya que emana y tiene origen en una decisión tomada por otro sujeto que ocupa materialmente el lugar de un poder constituyente o de reforma.

La adopción del principio de estabilidad presupuestaria en la Unión y sus desarrollos posteriores han permitido visualizar la transformación de la clásica "supremacía" constitucional y su habitual deslinde con la "primacía" del Derecho de la Unión, devaluando su virtualidad explicativa. Una doctrina que nuestro Tribunal Constitucional se ha esforzado en construir en sus dos declaraciones de 1992 y 2004, siguiendo una construcción escasamente realista. Buena parte de la dirección política de la economía —la más importante- se ha ido hacia Europa, en una "up stream" o corriente hacia arriba, vaciando las facultades constitucionales del Gobierno y del Parlamento. Empieza a hacernos falta a los juristas construir otras categorías más innovadoras e imaginativas que permitan explicar la realidad del fenómeno que en las elaboraciones anglosajonas se llama "pluralismo constitucional” o "pluralismo de constituciones".

Las densas normas europeas. La seria intensidad de la crisis económica ha reforzado el cumplimiento del principio de estabilidad presupuestaria sobre cuya exigencia podían albergarse dudas en 2007. Recordaremos, antes de describir el fenómeno, muy esquemáticamente la secuencia de normas europeas:

- El Tratado de Maastricht de 1992 estableció ya una fórmula de cooperación con los criterios de disciplina presupuestaria, ligados a la moneda única y a un sistema monetario europeo estructuralmente inestable o difícil de manejar.

- Más tarde, el Tratado de Ámsterdam de 1997 instituyó el código común de conducta fiscal que se concretó en el Pacto de Estabilidad y Crecimiento: preventivamente se obligaba a los Estados miembros a conseguir un saldo público cercano o superior al equilibrio y la vertiente correctora supuso un procedimiento de control de los déficits excesivos por el Consejo, sobre la base de recomendaciones de la Comisión.

- Tras la crisis del Pacto en los primeros años del siglo, causada por los incumplimientos de Francia y Alemania, y la posterior intervención dirimente del Tribunal de Luxemburgo, la prohibición europea se flexibilizó, determinando una mayor complejidad interpretativa de aquél a partir de 2006.

- Poco después vino la consagración formal del principio de solidez financiera, junto a otros relacionados con la estabilidad monetaria, en el Tratado de Funcionamiento de la Unión de 2007, donde se sitúa el principio de una economía abierta y de libre competencia como el techo ideológico de las políticas económicas en el espacio común.

- Años después llegaría la coordinación presupuestaria por medio del Semestre europeo que el Consejo aprobó en 2010 y que condiciona los procesos presupuestarios nacionales sobre todo en detrimento de las competencias de los parlamentos.

- El Pacto por el Euro plus alcanzado en 2011, bajo la forma de un acuerdo intergubernamental de los Estados de la zona euro y otros seis países más, introdujo ya el compromiso de su incorporación a las Constituciones o leyes de vinculación equivalente de los firmantes.

- La reforma y endurecimiento del Pacto vino instrumentada en 2011 por medio del "Six Pack", nombre empleado para el paquete de Reglamentos y una Directiva aprobados con un contenido complejo: mayores poderes otorgados a la Comisión, ratificación del semestre europeo, regla de gasto, automatismo en las sanciones, fortalecimiento del criterio de deuda frente al de déficit, nuevo procedimiento de prevención y corrección de los desequilibrios macroeconómicos excesivos, planificación presupuestaria a medio plazo con obligaciones de transparencia, coordinación y responsabilidades. Unido a ello, por ver primera se contempla la entrada en escena del Parlamento Europeo a través del diálogo económico con las restantes instituciones comunitarias y con los Estados afectados por las decisiones.

- El Mecanismo Europeo de Estabilidad, operativo desde 2012, responde a la idea de constitucionalizar un fondo de rescate, cuyos antecedentes fueron el sistema de préstamos bilaterales, la Facilidad Europea y el 
Mecanismo Europeo de Estabilización. Para crear el nuevo instrumento y evitar el rigorismo de los Tratados - cuya reforma habría requerido realizar una Convención o Conferencia Intergubernamental ad hoc-, se empleó el procedimiento simplificado de reforma del artículo 136 del Tratado de Funcionamiento y la posterior suscripción por los Estados de la eurozona de un Tratado intergubernamental constitutivo del Mecanismo. Se ganó en flexibilidad al propio tiempo que se perdió en democracia, aunque no lo viera así

el Pleno del Tribunal de Luxemburgo en la Sentencia "Pringle" de 27 de noviembre de 2012.

- Un nuevo acuerdo intergubernamental, vigente desde el 1 de enero de 2013 y del que se descolgaron el Reino Unido y la República Checa, es el Tratado de Estabilidad, Coordinación y Gobernanza en la Unión Económica y Monetaria o "Fiscal Compact", que promueve un tope más estricto de déficit estructural, programas de colaboración presupuestaria, coordinación de las políticas de endeudamiento, la constitucionalización doméstica de la "golden rule" y la verificación del cumplimiento de dicho aspecto por el Tribunal de Justicia de la Unión.

- Adicionalmente, dos nuevos Reglamentos están vigentes desde finales de mayo de 2013. Se trata del "Two Pack", con reglas para el seguimiento y evaluación de los proyectos presupuestarios y la corrección del déficit excesivo. La apuesta que allí se hace por organismos independientes de evaluación de las reglas fiscales ha dado lugar a la reciente creación de la Autoridad Independiente de Responsabilidad Fiscal en nuestro país.

Todo este conjunto normativo de lo más variado, donde hay principios y reglas en diversos cuerpos (Tratados, Reglamentos, Directivas... ) y "soft law" - como el Código de Conducta con directrices sobre formato y contenido de los programas de estabilidad y convergencia- se impone a las políticas fiscales nacionales y huelga decir que carece de un fundamento teórico incontestable, tanto por lo que se refiere a las cifras tope de déficit y de deuda — que se acordaron por el Consejo de Dublín en 1996- como en lo que respecta a los procedimientos que se arbitran, con excepciones según la importancia del Estado incumplidor. La monitorización de la política presupuestaria es evidente. Si viene de Europa, habrá que aprobarlo... parece ser el parámetro omnipresente de nuestra legislación, aunque ello reste enteros a la tradicional función presupuestaria de los Parlamentos, pues bien podríamos preguntarnos ¿dónde queda la democracia representativa en este escenario?

Una constitución europea material o decisionista. Asistimos hoy a un fenómeno difícil de describir jurídicamente y que adopta rasgos muy específicos. Se aproxima, pero sin ser ni una cosa ni la otra, tanto a una "constitución en sentido material" como nos enseñó Costantino MORTATI, diversa de la Constitución formal, como a una "constitución positiva o decisionista" según la caracterizó Carl SCHMITT; pero probablemente ambas tesis tampoco permiten comprender la especificidad del nuevo fenómeno. Es un lugar constitucional europeo donde se encuentran las decisiones políticas básicas que son materialmente supremas respecto de la economía, así como un conjunto de fuerzas sociales que inspiran y mantienen vigente algo semejante a una organización constitucional que limita las constituciones nacionales. Tenemos un Derecho Constitucional Económico Europeo, material y originario, pues está recogido fuera de una Constitución formal y, a menudo, fuera incluso de los Tratados constitutivos de la Unión, al venir disciplinado en relaciones intergubernamentales o en instrumentos de "soft law". Claro que esa Constitución positiva europea, desde la perspectiva nacional, se justifica en las cláusulas constitucionales de transferencia de competencia y/o soberanía a la Unión, pero desde la perspectiva del ordenamiento comunitario posee sus propios mecanismos de validez.

Esta constitución material o positiva europea, en cuanto incluye las decisiones políticas básicas sobre la economía y buena parte de la dirección política de la misma, ha sido aprobada en España sin apenas debate parlamentario ni, menos aún, debate ciudadano alguno ante la opinión pública. No en balde, en las elecciones europeas tiende a hablarse de menudencias o de cuestiones internas, al pensarse que los detalles de la organización de Europa no pueden interesar a los ciudadanos. Ahora vemos que no es así. Es menester hacer un esfuerzo de pedagogía y no dar carta de representación a un poder constituyente europeo, silente, sin publicidad ni discusión internas.

Buenas y malas noticias. Reformas pendientes. El euro, la moneda única, ha sobrevivido airoso a la crisis, pese a que muchos no lo creían. Pero el gobierno europeo de la economía se ha revelado día a día bastante ineficaz por insuficiente. No puede bastar con supervisar el cumplimiento de unos topes de déficit y deuda por los Estados y con coordinar nuestros Presupuestos para gobernarnos eficazmente. Tenemos una unión monetaria pero no una unión económica. Hemos cambiado la dirección de la política económica por los Gobiernos nacionales —y en España sin reformar la Constitución ni tener siquiera una cláusula constitucional europea- por un sistema europeo muy incompleto. La constitucionalización europea de la crisis es una consecuencia colateral de la moneda única y la coordinación presupuestaria, pero nos faltan otros ingredientes. El Parlamento Europeo sigue jugando un papel 
secundario. No hay un supervisor bancario común. Tampoco tenemos una Reserva federal, pese a que las funciones del Banco Central Europeo hayan ido creciendo en la práctica (el Tribunal Constitucional Federal Alemán acaba de preguntarle al Tribunal de Justicia de la Unión, en una cuestión prejudicial, por la regularidad de esta evolución y extensión de los poderes implícitos). Finalmente, persiste el debate sobre los "Stability Bonds" o la europeización de la deuda y los muy distintos intereses de la deuda soberana de los Estados miembros.

No parece haber más salida que reforzar la dirección de la política económica europea y antes o después, al ritmo que se pueda, modificar los Tratados. Los Estados miembros están actualmente inermes para defenderse por sí solos ante la crisis. No podemos seguir disociando la política monetaria de la política fiscal, ni la capacidad de endeudamiento del resto de la política económica. Nos faltan más instrumentos europeos. A la crisis de Europa no parece haber más salida que más Europa: reforzar el gobierno común de la economía.

La paradoja del federalismo. El marco normativo europeo que hemos expuesto tiene una intensa densidad normativa, tan densa que apenas deja marco de maniobra a las Constituciones y a las leyes domésticas, viniendo a ocupar el espacio constitucional. Los Estados se limitan a trasladar esas reglas a las Constituciones y a las leyes y a un conjunto de decisiones en buena medida predeterminadas. En Europa la paradoja — como ha expuesto FABRINI- es que la ausencia de una organización federal y la defensa a ultranza de la soberanía de los Estados miembros ha provocado justamente el efecto contrario: una mayor centralización y una sensible pérdida o menosprecio de la soberanía en el funcionamiento interno. El sistema europeo es mucho menos garantista para los Estados que lo que sería un modelo federal. Una lección que debería hacer reflexionar a los partidarios de las relaciones intergubernamentales.

¿Quién se atrevería a dar instrucciones tan precisas e imperativas — pese a presentarse como meras condiciones- $a$ alguien que no fuera su subordinado como son las que se indican al Gobierno español en el Memorandum of Understanding on Financial Sector Policy Conditionality, el llamado "MoU"? Claro está que los subordinados no suelen deber a sus superiores tanto dinero como el que ahora nos prestan. Esta Decisión del Consejo Europeo parece comprender las condiciones que establece como instrucciones redactadas al modo de un legislador estatutario inglés. Recordemos que el viejo ORLANDo nos enseñaba que la capacidad de dictar instrucciones al subordinado es una clara muestra de jerarquía. Si Bodino hubiera leído el "MoU”, habría mencionado esta facultad de establecer condiciones económicas como uno de los signos sensibles de la soberanía —europea- de los que hablaba junto a la capacidad de acuñar moneda.

\section{EL DESARROLLO EN UNA ESPECÍFICA LEY ORGÁNICA DEL ARTÍCULO 135 CE}

Las prisas no favorecen buenas decisiones ni normas de calidad. La aprobación de la Ley Orgánica 2/2012, de Estabilidad Presupuestaria y Sostenibilidad Financiera fue tan precipitada como la Reforma constitucional a la que viene a desarrollar. Las Cortes apenas dedicaron dos meses a su tramitación y el Consejo de Estado advirtió algunos defectos técnicos de una Ley que ya ha sido modificada tres veces (las dos últimas a finales del año pasado, con apenas un mes de separación), confirmando esa precipitación. Además tuvo un apoyo menor al apostar por una versión más restrictiva que la que resultaba del acuerdo bipartidista que dio lugar a la Reforma.

El anclaje constitucional del sistema dentro de las competencias estatales. A pesar de la insuficiencia de los antecedentes legislativos que se aprobaron a finales de 2001, el Tribunal Constitucional tuvo ocasión de significar en la STC 134/2011, poco antes de la aprobación de la Reforma del artículo 135 CE, la competencia del Estado —ex artículo 149.1 apartados 13 y 14 CE- para frenar el gasto público, imponer topes máximos de crecimiento del mismo y acomodar la actividad financiera de las Comunidades Autónomas a las medidas estatales para alcanzar la estabilidad presupuestaria, por ser un principio y un objetivo de la política comunitaria que recoge el artículo 126 TFUE. Esa sentencia fue seguida por otras doce y ahora ya se cuenta con el nuevo canon de constitucionalidad que vincula a todos los poderes públicos y legitima el establecimiento de límites presupuestarios a las autonomías por exigencias del principio de estabilidad presupuestaria.

A la vista de esa jurisprudencia, algunos autores entendieron que no había hecho falta acudir al expediente de Reforma constitucional, bastando realizar los cambios en la legislación ordinaria de estabilidad y en la LOFCA. Sin embargo, no nos parece que tenga mayor sentido pretender una economía procedimental, imposible a la vista de los numerosos problemas que la Reforma afronta e incluso deja sin resolver. Los topes de endeudamiento son ahora explícitos y obligatorios, resultando reforzados en su eficacia con una regulación constitucional sustantiva conexa a los títulos competenciales. Con todo, el Tribunal Constitucional tendrá que resolver el recurso promovido por el Gobierno de Canarias contra la Ley Orgánica. Ojalá que llegue pronto esa resolución.

La estabilidad-sostenibilidad financiera y otros complementos de la idea. La Reforma constitucional ha consagrado la estabilidad presupuestaria como "valor verdaderamente estructural y condicionante de la capacidad de 
actuación del Estado, del mantenimiento y desarrollo del Estado Social que proclama el artículo 1.1 de la propia Ley Fundamental y, en definitiva, de la prosperidad presente y futura de los ciudadanos". Ello determina la idea de la "sostenibilidad financiera" que intitula la Ley Orgánica de desarrollo. Estabilidad-Sostenibilidad como un bien constitucionalmente protegido y a la par un objetivo de la política comunitaria en el Derecho Europeo. En el artículo 4.2 de la ley se define ahora la sostenibilidad financiera como "la capacidad para financiar compromisos de gasto presentes y futuros dentro de los límites de déficit, deuda pública y morosidad de deuda comercial”3.

Estabilidad-Sostenibilidad como una actuación permanente de todas las Administraciones públicas que ha de orientar los procesos de elaboración, aprobación y ejecución de los Presupuestos y que a la originaria visión unidimensional vinculada a la deuda pública se añade ahora también la idea de la sostenibilidad de la deuda comercial, esto es: el cumplimiento del periodo medio de pago a proveedores previsto en la normativa sobre morosidad. En la cultura anglosajona suele considerarse ligada a una cultura de buena administración. También entre los economistas parece predominar la conciencia de que el endeudamiento es malo. Y entre los juristas europeos, alguien con tanta autoridad como Paul KIRCHOFF ha defendido el principio con rigurosas razones, pidiendo pasar de una comunidad de endeudados a una comunidad de ahorradores, con el fin de que el progreso actual no resulte exclusivamente financiado por las generaciones siguientes. Complementariamente a ese principio están los de plurianualidad, transparencia, eficiencia en la asignación y utilización de los recursos, responsabilidad y lealtad institucional, recogidos en la ley.

Vinculación de todo el sector público con la cláusula de "no bail out". Así se desprende de la Ley orgánica y del código presupuestario de la Unión Europea, recogiendo la valoración de la Stabilitätsgemeinschaft realizada por el Tribunal Constitucional Federal alemán. Cada Administración debe asumir su responsabilidad por incumplimiento sin que pueda cómodamente trasladarse a la Hacienda superior. Se trata de una corresponsabilidad directa de cada una de las Administraciones, que deben acostumbrarse a vivir sin el paraguas o el airbag del Estado y debe interpretarse conforme al criterio de lealtad institucional en el ejercicio de las competencias, recogido en numerosas sentencias del Tribunal Constitucional, valorando el impacto de las propias actuaciones. Si el freno al endeudamiento se impone en el Derecho Constitucional europeo, su aplicación real se juega en buena medida —aunque no sólo- en la encrucijada de la descentralización territorial interna.

Instrumentación del principio: su especificación en tres reglas fiscales numéricas. Estas configuran el núcleo duro de la Ley orgánica, asumiendo las previstas en el Derecho de la Unión, debiendo cumplirse plenamente en 2020, cuando se supere el período transitorio actualmente fundado en una senda de ajuste anual del déficit y endeudamiento. Veamos brevemente el significado de las reglas:

- Límite de déficit estructural (3\% en el PEC, 0,5\% en el TECG, 0,4\% en la LOEPSF). Es prácticamente una prohibición de déficit estructural: o equilibrio o superávit. ¿Qué es el déficit estructural? Un concepto jurídico indeterminado, una noción muy discrecional, como ha señalado Rodríguez Bereijo, lo que dificultará enormemente su control. La ley lo define como "un déficit ajustado del ciclo, neto de medidas excepcionales y temporales”. ¿Quién determina y controla eso? ¿Cumpliremos el tope fijado legalmente en 2020, ahora que debemos estar por un 6,5\% del PIB?. Como omisiones de la Ley orgánica cabe anotar el silencio con la distribución del límite de déficit entre el Estado y las Comunidades Autónomas —como pedía regular la letra a) del artículo 135.2 CE - y la ausencia de regulación sobre la metodología y procedimiento para el cálculo del déficit estructural — señalado en la letra b) del mismo precepto—, lo cual traduce un incumplimiento formal de las previsiones exigidas por la Constitución.

- Regla de freno al gasto público. Supone un par de cosas: por un lado tendrá que darse una lógica vinculación entre el crecimiento del PIB de medio plazo de nuestra economía y el gasto público, y por otro lado se determina el único destino posible de los mayores ingresos que pudieran obtenerse respecto de los previstos inicialmente.

- Límite del volumen de deuda pública y autorización estatal. La ley distribuye el tope del 60\% del PIB nacional en términos nominales a razón de un 44\% para la Administración central, el 13\% para las Comunidades Autónomas y el 3\% para las Entidades Locales. Además, cada Comunidad Autónoma no debe sobrepasar el 13\% de su PIB regional. Unos umbrales que hoy se presentan muy deseables de lograr, cuando hemos triplicado en endeudamiento conjunto los límites anteriores a la crisis y nos acercamos a un billón de euros, tras haber cerrado 2013 con un volumen del 93,7\% del PIB. Entre las Comunidades, Baleares (23,8\%), Cataluña (27,2\%), Castilla-La Mancha $(28,7 \%)$ y Comunidad Valenciana $(29,8 \%)$ encabezan el grupo que incumple. Por debajo del 13\% solo están Asturias, Canarias, Madrid y País Vasco.

3 La redacción proviene de la Ley Orgánica 9/2013, de 20 de diciembre, de control de la deuda comercial en el sector público. 
La fijación de los objetivos globales que dimanan de las reglas numéricas se realiza por el Ministerio de Hacienda y la propuesta gubernamental debe ser convalidada por el Congreso y el Senado. El procedimiento para ello bien podría mejorarse, bastando con la intervención del Congreso como sucede ahora con la convalidación de los Decretos-leyes.

Las sanciones y medidas de ejecución forzosa. La Ley orgánica contiene todo un capítulo dedicado a las facultades de control, distinguiendo varios tipos de medidas — preventivas, correctivas y coercitivas- que trasladan el procedimiento de intervención europea a la intervención federal en desarrollo de la Constitución. Sin embargo, pese a las apariencias, ambas situaciones no creemos que sean suficientemente homogéneas y aquí pueden empezar los problemas del "copy paste" de la regulación europea. Aunque el procedimiento establecido en la Ley pueda parecer bastante lógico en el papel, está por constatarse su eficacia en la práctica.

La aplicación de las medidas preventivas depende, como es lógico, de toda una actividad previa de seguimiento y evaluación de los datos de ejecución de los Presupuestos, por lo que la realización de ajustes en el gasto público de las distintas Administraciones deviene en el primer mecanismo para garantizar que al cierre del ejercicio se de cumplimiento al objetivo de estabilidad. La Ley contempla otras medidas que se refieren a distintos niveles de gobierno:

- Limitación de las operaciones de endeudamiento a las estrictas de tesorería cuando el volumen de deuda pública se sitúe por encima del $95 \%$ de los límites de conjunto y de cada nivel territorial.

- Aplicación de los mecanismos de revalorización y ajuste del sistema de pensiones para garantizar el equilibrio presupuestario y la sostenibilidad del sistema de Seguridad Social.

- Medidas para garantizar el cumplimiento de los períodos de pago a proveedores de las Comunidades Autónomas y Entidades Locales (introducidas por la Ley Orgánica 9/2013).

- Advertencia de riesgo de incumplimiento, dirigida por el Gobierno a a las Comunidades Autónomas y Entidades Locales que presenten problemas para cumplir el objetivo de estabilidad presupuestaria, el objetivo de deuda pública o la regla de gasto.

- Las medidas automáticas de corrección que contempla la ley son:

- Autorización por el Estado de todas las operaciones de endeudamiento de las Comunidades Autónomas en las que se constate, a través de los informes elaborados por la Autoridad Independiente de Responsabilidad Fiscal o el Ministerio de Hacienda, que existe incumplimiento de las reglas fiscales numéricas.

- Autorización de todas las operaciones de endeudamiento a largo plazo de las Corporaciones Locales que participan en la cesión de impuestos estatales que hayan incumplido los objetivos de estabilidad o de deuda pública, correspondiendo otorgarla al Estado, o en su caso a la Comunidad Autónoma que tenga atribuida la tutela financiera.

- Informe preceptivo favorable del Ministerio de Hacienda para la concesión o suscripción de subvenciones y convenios por la Administración Central con Comunidades Autónomas que hayan incumplido las reglas fiscales.

- Medidas de corrección en relación con las Comunidades Autónomas que superen en más de treinta días el plazo máximo de pago a sus proveedores, persistiendo su morosidad durante dos meses consecutivos desde la actualización de su plan de tesorería. Han sido introducidas por la Ley Orgánica 9/2013 y pueden consistir en: adopción de un acuerdo de no disponibilidad; autorización estatal, gradual por tramos, de todas las operaciones de endeudamiento a largo plazo; inclusión de nuevas medidas en la actualización del plan de tesorería de la Comunidad y retención de los importes a satisfacer a la Comunidad Autónoma por los recursos de los regímenes de financiación para pagar directamente a los proveedores de aquélla.

- Obligación de elaborar un plan económico-financiero que permita, en dos años, el cumplimiento de las reglas fiscales4 y presentación de planes de reequilibrio por las Administraciones que hayan incurrido en alguna de las circunstancias excepcionales advertidas en el artículo 135 de la CE, realizando informes de seguimiento, sobre todos estos planes, el Ministerio de Hacienda.

Las medidas coercitivas, también de automática aplicación, se hallan directamente ligadas a la falta de adop-

4 La Ley Orgánica 9/2013 ha corregido el limitado horizonte temporal de los planes económico-financieros que figuraba en la originaria redacción del artículo 21.1 LOEPSF, ampliándolo ahora al «año en curso y el siguiente». Debe recordarse que la legislación anterior a la LOEPSF fijaba su duración en tres años. Los planes de reequilibrio no tienen fijado un plazo para la corrección, sino que recogerán la senda prevista para alcanzar los objetivos de estabilidad presupuestaria o de deuda pública. 
ción de los anteriores instrumentos de planificación presupuestaria o la incapacidad de los mismos para resolver la situación de incumplimiento o cuando persista una situación de morosidad en el pago a proveedores. Son las siguientes:

- Acuerdos de no disponibilidad de créditos, efectuando su correspondiente retención.

- Constitución de un depósito con o sin intereses en el Banco de España y pudiendo convertirse en multa coercitiva.

- Envío de una comisión de expertos para que valore la situación económico-presupuestaria de la Administración afectada.

Si todo lo anterior no fuera suficiente, entrarían en juego las medidas de cumplimiento forzoso. Estamos ante facultades extremas, huérfanas de uso en el ámbito autonómico (hay algún antecedente en el local), representando no un control sobre los actos sino sobre los órganos mismos de las Comunidades Autónomas, pudiendo llevar a la desaparición del autogobierno. La Ley orgánica reproduce las previsiones del artículo 155 CE sin añadir nada más que los trámites procedimentales — que ya están en la Constitución-, no especificando ni las medidas que pueden adoptarse ni quienes serán las personas responsables. La secuencia será: requerimiento del Gobierno, autorización del Senado por mayoría absoluta y adopción de las "medidas necesarias" sin que se indiquen cuáles serán éstas, salvo dar instrucciones a todas las autoridades de la Comunidad Autónoma. Esa ambigüedad es lógica en la Constitución, pero no en una Ley orgánica de desarrollo que cumple una función constitucional.

El verdadero punctum dolens de la Reforma: la gravedad de la intervención federal. No podemos desdramatizar lo que supone este control excepcional que puede llevar a la disolución del órgano o la suspensión de la autonomía. ¿Podemos imaginar esa situación en Cataluña o el País Vasco sin llegar a una situación de práctico enfrentamiento civil? ¿Es realmente inteligente la solución? Los Estatutos de ambas Comunidades, durante la II República, regularon una intervención estatal y convendría recordar los sucesos del 6 de octubre de 1934, bajo el Gobierno de Lerroux, que acabaron con la declaración del estado de emergencia, la detención de los miembros del Gobierno catalán y la suspensión fáctica de la autonomía por una ley que el Tribunal de Garantías Constitucionales declaró inconstitucional por no venir prevista en la Constitución. Esto aplicado a unas décimas de déficit público es matar moscas a cañonazos.

Una interpretación constitucional correctora de la ambigüedad de la Ley: la necesidad de integrarla con la lógica constitucional. El artículo 155 CE ha estado hasta ahora en la Constitución como una amenazante espada de Damocles para no tener que ser usada, una ultima ratio. Y creemos que sería inteligente disociar la gravedad de las sanciones por incumplimiento y la intensa vinculación con el cumplimiento de esos objetivos nacionales y europeos, relativizando y normalizando los controles mediante la intervención de órganos jurisdiccionales o autoridades independientes. Tratando de hacer de los defectos virtud y a la búsqueda de una adecuada ingeniería constitucional que corrija los excesos de la Ley Orgánica desde la Constitución, debe reclamarse la lógica aplicación de las sucintas previsiones del artículo 155 CE con un principio de proporcionalidad en materia de sanciones que suponga una escala gradual de medidas:

- La subrogación del Gobierno en el acto autonómico, o la sustitución temporal de los titulares de los órganos autonómicos por delegados o altos comisionados nombrados por el Gobierno central,.

- La ejecución subsidiaria y forzosa a cargo del Estado, o quizás mejor la avocación temporal de la competencia.

- Sólo si nada de lo señalado bastase, podrían suspenderse los órganos de autogobierno (disolución del Parlamento o destitución del Presidente), pero no antes.

En todo caso, la adopción de estas medidas es muy problemática y resbaladiza ante la indeterminación de la Constitución. Nuestro modelo recuerda a la técnica de coacción del federalismo alemán, que no ha tenido acogida en muchos otros ordenamientos. La Constitución italiana permite sustituir a los órganos de las Regiones en ciertos casos. Y en Austria figura la avocación de la competencia. Santiago MuÑOz MACHADo ha recordado el clásico debate en época de la República de Weimar sobre si la coacción estatal reclama o no una decisión judicial previa.

La necesidad de ordenar un control ordinario de la estabilidad. La aplicación del artículo 155 CE plantea muchos problemas y hubiera sido preferible optar por instrumentos ordinarios de control jurisdiccional de los incumplimientos de la estabilidad presupuestaria y no por una coerción estatal que, por su misma desproporción, es muy probable que nunca se llegue a aplicar. El vicio de inconstitucionalidad de la estabilidad presupuestaria no se corresponde con esa facultad extraordinaria que se ha trasladado al ordenamiento interno desde el europeo sin apenas reflexión. Pero nos tememos que algunos economistas no compartirán este entendimiento. 
Incertidumbres sobre la violación de las reglas fiscales: su relativa indeterminación. Pese a todas las reglas que aparecen en la Ley, no estamos ante una norma clara y desprovista de ambigüedades. No es ocioso señalar que el déficit estructural deberá ser estimado ya que, como ha señalado RoDRícUEZ BEREIJo, no es una variable económica que pueda observarse sin más. Otro tanto sucede con lo que sea la deuda pública, dada la amplitud de formas y títulos que la misma presenta y que no pueden reflejarse en la Constitución ni en la ley de desarrollo. ¿Las incertidumbres pueden violar el principio de taxatividad de las prohibiciones, incluidas las constitucionales? Nos parece que es un juicio jurídico y presupuestario demasiado técnico para posibilitar un control político y automático del Gobierno que, a la postre, podría acabar engendrando monstruos si no se actúa con realismo y prudencia.

Superposición de controles y naturaleza del vicio en el control de la estabilidad presupuestaria. ¿Una Autoridad Independiente, el Tribunal Constitucional, el Tribunal de Cuentas o los tres a la vez? La cuestión no nos parece que esté bien resuelta. ¿Es un nuevo vicio de inconstitucionalidad, por violación de un principio que debe corresponder a la jurisdicción constitucional o de mera legalidad y debe corresponder al órgano fiscalizador por su especialización? ¿Cómo se compagina la intervención de estas tres instituciones de evaluación y control? De forma muy esquemática tenemos:

- El Tribunal Constitucional, que controla la constitucionalidad de las leyes por mandato constitucional, pero cuya jurisdicción no está técnicamente preparada para esta función presupuestaria y contable (casi nadie sabe de números allí). ¿Debe ser un control material como ha propuesto Rodríguez Bereijo y nosotros mismos hemos apuntado? Ello requeriría, indudablemente, novedades procesales e introducir medidas correctoras del daño y unos breves plazos legales. Pero no hay previsiones normativas en la Ley del Tribunal. Recientemente, el Tribunal Constitucional de Renania del Norte Westfalia declaró inconstitucional una Ley de Presupuestos del Land por violar el freno al endeudamiento. Y más recientemente hemos visto como el Tribunal Constitucional de Portugal ha resuelto en breves plazos diversas impugnaciones. El "Fiscal Compact" permite a la Comisión someter el incumplimiento de los topes de déficit y deuda ante el Tribunal de Justicia de la Unión con audiencia del Estado miembro. ¿Porqué no se ha trasladado un esquema similar?

- El Tribunal de Cuentas, al que corresponde ser el supremo órgano fiscalizador de las cuentas y de la gestión económica del estado (art. $136 \mathrm{CE}$ ). Podría ejercer un control preventivo. Pero también represivo o sucesivo. En Italia se ha discutido si podría jugar un papel auxiliar ejercer una acción ante el Tribunal Constitucional y/o emanar un informe junto a otras instituciones (por ejemplo: el análogo órgano autonómico de control externo si existe).

- Una Autoridad Independiente de Responsabilidad Fiscal, de reciente creación por la Ley Orgánica 6/2013, que dice ser instrumento complementario — de contenido no necesario, según entendemos, por no venir predeterminado constitucionalmente- de la Ley de desarrollo del artículo 135 CE. Se acoge así formalmente recomendaciones internacionales y de la Unión Europea, aparte de un imperativo señalado en el "MoU", con funciones de informe y evaluación de las reglas fiscales, pero adscribiéndose al Ministerio de Hacienda, con lo que no parece que empecemos muy bien con su independencia. ¿No hubiera sido mejor optar por un Consejo de Estabilidad como en Alemania y hacer uso de las competencias que ya disponen el Tribunal de Cuentas y el Tribunal Constitucional?

\section{LA CONSTITUCIÓN DOMÉSTICA: UNA CONSTITUCIÓN SIN APENAS DERECHO CONSTITUCIONAL}

El impacto constitucional de la crisis. La Constitución española se ha resentido seriamente en su consistencia normativa y legitimidad democrática a causa de la crisis económica, y la paralela centralización en —la distanteEuropa de la política monetaria, y de esos umbrales de déficit y deuda que atienden a la estabilidad presupuestaria y demandan una coordinación de los Presupuestos y otras consecuencias. Al revés que en la Unión, puede pensarse que tenemos en España una Constitución con cada vez menos Derecho Constitucional. Por muy variadas razones, que enunciaremos primero en su conjunto para, a continuación, detallar algunas someramente.

Consecuencias constitucionales del impacto. El llamado semestre europeo ha tenido un fuerte impacto en la devaluación de la función presupuestaria de las Cortes Generales. El Gobierno se ha visto obligado, de forma sobrevenida y por las dimensiones de la crisis, a aplicar un programa de gobierno basado en la austeridad que no fue su programa ante el cuerpo electoral y por el cual obtuvo la confianza de sus representados. Los problemas de financiación autonómica y los subsiguientes recortes en los servicios públicos han debilitado la cohesión del Estado autonómico y espoleado a las fuerzas separatistas en Cataluña. La rebaja en los niveles de las prestaciones sociales de décadas han puesto en solfa la viabilidad de nuestro Estado de bienestar y se han convertido en una seria amenaza para la misma subsistencia de los derechos sociales y principios rectores. La clara opción por ciertas fuentes del Derecho más autoritarias, como son los Decretos-leyes, y en detrimento de otras fuentes más 
participativas y democráticas como son las leyes, han generado un vaciamiento del parlamentarismo en muchas cuestiones centrales. El treinta y cinco aniversario de la Constitución de 1978 que se cumple este año no parece un buen momento para celebrar nada y lamentamos tener que ser realistas. La mayor parte de las instituciones constitucionales (el Tribunal Constitucional, el Tribunal de Cuentas, el Consejo General del Poder Judicial, la Corona, el Banco de España...) están sumidas en una seria crisis de funcionamiento o de legitimidad democrática por no decir casi todas. Son precisos nuevos acuerdos y reformas; cuanto más tarde se comience más difícil será. Es tiempo de actuar y no de seguir dilatando las decisiones.

La prudencia no es siempre la iuris prudencia en vez de la audacia. Frente a estas poderosas razones, a menudo se sostiene con — falsa — prudencia que no es el momento de acometer reformas. Una variante de la clásica máxima ignaciana que aconseja que en tiempos de turbulencias no se acometan mudanzas. Pero ¿cuándo lo fue antes...? y ¿cuándo lo va a ser más adelante...? Si admitimos que ciertas fuerzas nacionalistas puedan bloquear la Reforma constitucional de las instituciones, como hasta ahora ha ocurrido, habrán conseguido exitosas el objetivo final que albergan algunas de ellas: destruir la nación y el Estado. Es preciso un pacto entre todas las fuerzas estatales para iniciar el estudio de una seria reforma constitucional y recuperar la capacidad de pactar, transigir (que es precisamente aquello que CÁNOVAS DEL CASTILLO nos enseñó en qué consistía el arte de la política) y romper el nudo de ese círculo vicioso. Que únicamente se excluya de ese pacto quien lo desee como sanción a su falta de empatía. Quizás pudiera comenzarse por algo sencillo para recuperar el hábito de generar consensos. La opción podría ser la reforma del obsoleto Reglamento parlamentario del Congreso.

La reforma constitucional como mecanismo de defensa de la Constitución. La reforma constitucional es moneda común en los países de nuestro entorno. Un mecanismo habitual de defensa de la Constitución en cualquier teoría de la Constitución. Así ha sido en Estados Unidos con sucesivas enmiendas. Más aún en Alemania con cincuenta y siete reformas. Ha habido veinticuatro en Francia. Y treinta y cuatro leyes constitucionales en Italia. España no puede ser un país bárbaro en el que sólo se sabe construir una Constitución sobre las ruinas de otra. No repitamos la maldición de nuestros siglos XIX y XX.

Las fuentes del Derecho: legislar por Decreto-ley o "soft-law". Ha habido una profunda alteración de la ubicación del sistema de fuentes en su sentido en el Estado de Derecho y la división de poderes mediante un constante incremento del "soft-law" en la Unión y de los Decretos-leyes en España.

En 1992 el jurista y eurodiputado francés Maurice DUVERGER alertaba sobre los riesgos de que la liebre liberal terminase adelantando a la tortuga europea. Y quizás, espoleados por la crisis de las finanzas, en estos últimos años hemos visto como un cada vez más inaprensible ordenamiento de la Unión está conformándose como el marco propicio de superación del "viejo" constitucionalismo social y democrático de Derecho, reflejado en las leyes políticas fundamentales de los Estados miembros. Quizás se deba a lo diabólicamente ineficaces que suelen ser los procesos de toma de decisiones en la Unión, como acertara a decir el expresidente GoNzÁLEZ, lo que haya acentuado la tendencia hacia fórmulas débiles de coordinación política — como fue el propio Pacto de Estabilidad y Crecimiento en sus primeras formulaciones-y de coerción jurídica que han ido acentuándose en la lucha contra la crisis. Todo el mayor intervencionismo comunitario se deja ver en muchas muestras de "soft law" y en formulaciones competenciales híbridas. Un buen ejemplo lo tendríamos en los progresos que se han ido registrando últimamente en la lucha contra el fraude y el intercambio de información, donde la ausencia de una verdadera conciencia fiscal europea ha impedido cosechar éxitos por la vía de aproximar efectivamente las legislaciones tributarias de los Estados miembros. Otro mucho más elocuente es el que se alcanza desplazando competencias presupuestarias nacionales, aunque sea a costa de restringir las facultades parlamentarias. Al final, de la crisis saldremos con una sensación de gobernanza sin gobierno y sin responsabilidad por el circuito cerrado de decisiones empleado en la compleja relojería institucional de la Unión.

Junto a los instrumentos de derecho blando han prodigado también normas de variado rango para afrontar la crisis. Recomendaciones y códigos de conducta yuxtaponiéndose a Reglamentos, Directivas y Tratados al margen de los Tratados originarios, aunque previendo su futura incorporación a estos últimos. El Pacto por el Euro Plus, el Tratado del MEDE o el "Fiscal Compact" dan muestra de ese fenómeno de "desconstitucionalización" europea, motivado por los obstáculos que determinados Estados miembros sitúan a la reforma de los Tratados de la Unión. La crisis nos pilló definitivamente mal organizados e igualmente desprovistos de una buena Constitución económica. La tortuga europea deberá adaptar sus normas a la liebre financiera.

$Y$ en nuestro ámbito interno: una barbaridad. Últimamente se han dictado nada menos que cuarenta y ocho Decretos leyes en lo que va de Legislatura. No es exagerado decir que durante la crisis se ha gobernado por Decreto-ley. Se ha emanado una legislación de emergencia que termina afectando seriamente a muchas cuestiones que distan de ser coyunturales. Todas estas disposiciones del Gobierno con rango de ley se han convalidado, claro está, 
por el Congreso de los Diputados y únicamente en once casos se ha iniciado su tramitación como ley. Confiamos en que el sistema no se mantenga en lo que resta de la X Legislatura o en la siguiente. Es verdad que las estadísticas demuestran que todos los nuevos Gobierno comienzan llenando el "BOE" de estas disposiciones y luego se van calmando, pero estos números no tienen parangón.

Dada la casi imposibilidad real, en la práctica, del control político — por el Congreso— y del control jurídico - por el Tribunal Constitucional—, tanto del requisito habilitante que entraña la "extraordinaria y urgente necesidad" como de la reserva negativa de materias vedadas conforme al artículo 86 CE, es razonable empezar a pensar en la necesidad de reformar la Constitución para que la posterior tramitación como leyes de los Decretos-leyes no sea una opción sino una obligación constitucional (apartado 3), con el fin de permitir la discusión con las minorías parlamentarias y propiciar la publicidad de esas medidas adoptadas con tanta urgencia.

La huida hacia arriba de la función presupuestaria. Este es el efecto más destacable del semestre europeo atrayente hacia el Consejo (con propuestas de la Comisión) de las competencias que en la materia ejercían los Ejecutivos y Legislativos nacionales. La reforma europea entraña así una pérdida de la centralidad de las Cortes en la aprobación de los Presupuestos y la alteración del tradicional equilibrio entre Gobierno y Parlamento ni transmite mayor seguridad ni, sobre todo, fortalece el esencial principio democrático representativo y la subsiguiente legitimidad de las decisiones. El procedimiento arroja dificultades de seguimiento y no permite una clara identificación de la responsabilidad política última del órgano o institución que impulsa los cambios que deberán introducirse en los proyectos presupuestarios nacionales. ¿Qué decisiones pueden tomar las Cortes Generales cada año al aprobar la Ley de Presupuestos? Poco espacio queda a tan importante instrumento normativo si se convierte al titular de la competencia suprema para aprobarlo en un mero registro de esas decisiones. El déficit democrático del sistema presupuestario parece innegable y a ello se suma ahora, de manera mucho más palmaria que antes de producirse la Reforma constitucional, la expropiación de la función presupuestaria y la abdicación del Parlamento de su papel vigilante sobre el endeudamiento, con tal que la Deuda se sujete a las condiciones legales de la emisión.

Los recortes en derechos y políticas sociales. La crisis financiera ha mostrado que es precisa cierta austeridad en el Estado de bienestar, que no puede crecer constantemente en sus ayudas. Debería centrarse en las prestaciones más esenciales: en la educación y la sanidad públicas y las prestaciones de la seguridad social. No en dar múltiples subvenciones ni en reconocer nuevos derecho sociales, sin calcular su impacto presupuestario, tal y como hicieron generosamente los Estatutos de Autonomía de Cataluña y Andalucía, intentando transformar meros principios rectores en manos de las leyes y las coyunturas financieras en verdaderos derechos fundamentales plenamente exigibles. Un intento de transustanciación que frenó la STC 31/2010. Ya hemos advertido que los derechos sociales no tienen por qué ser baratos pero deben ser austeros. Así, el Pacto por el Euro plus recomendaba reforzar la coordinación económica y mejorar la competitividad y para ello: reformar los sistemas de pensiones, y de atención sanitaria y prestaciones sociales... Pero, si sólo aplicamos recortes y no racionalizamos la gestión de estos servicios públicos correremos el riesgo de degradarlos hasta hacerlos irreconocibles. Las prestaciones de la seguridad social, por ejemplo, deben revisarse desde la lógica de la necesidad y la proporcionalidad e incrementar la inspección y el control del sistema.

El apagón del circuito democrático representativo. En toda división de poderes existe un circuito democrático representativo organizado conforme a una lógica muy distinta del circuito de garantías constitucionales. ¿Dónde ha quedado durante el escenario de crisis económica ese circuito representativo y participativo de los ciudadanos? El Gobierno se vio obligado por las dimensiones de la crisis a modificar su programa electoral, que votó el pueblo en una concurrencia electoral, pero no se sintió obligado a plantear la cuestión de confianza ante el Congreso de los Diputados como aconseja el artículo 112 de la Constitución. Tendemos a creer que puede modificarse el programa electoral y de investidura sin necesidad de plantear al Parlamento un voto de confianza. Si el programa electoral, sobre el que se erige la relación de confianza con los representados, se puede modificar libremente de forma sobrevenida por el Gobierno, sin siquiera someterse al control de los representantes del pueblo en el Congreso, nos preguntamos qué tipo de democracia representativa y de sistema parlamentario tenemos. Carece de sentido constitucional creer que la cuestión de confianza está en la ley fundamental como un jarrón chino o instrumento ornamental. El circuito democrático representativo no funciona en los dos niveles y es menester recomponerlo.

\section{CONCLUSIÓN.}

A los anglosajones les gusta decir "Let the dust settle". Esperemos a que el polvo se asiente... Urge esperar a que acabe la crisis para ver lo que realmente ha ocurrido y no apresurarnos en el pesimismo. Aunque probablemente nada vaya a ser ya lo mismo en los Estados europeos y en la Unión y deberíamos empezar unas serias reformas en los dos niveles constitucionales. En los Tratados de la Unión y en el Estado. Y, entre ellas, una reforma de la Constitución y no sólo de las leyes por el impacto político y legitimador — no sólo jurídico y ordenador- que 
ello tiene.

No sigamos improvisando, hagamos lo mismo que han hecho siempre todos los demás Estados constitucionales de nuestro entorno: dialogar, transigir, pactar y reformar sus Constituciones y las leyes que las desarrollan. España no es diferente.

Pero no podemos pretender conocer con certeza el alcance de esas reformas antes de que se sienten las fuerzas políticas y las estudien en la mesa de negociaciones. No pongamos los bueyes por delante del carro, ni dejemos que el temor a equivocarnos nos paralice. 